\title{
Outpatient Visits by Dentists: A Nationwide Cohort Study in Taiwan
}

\author{
Chang-Ta CHIU ${ }^{1}$, Shu-Min HUANG ${ }^{2}$, Yu-Wen $\mathrm{LIN}^{2}$, Ming-Chung $\mathrm{KO}^{3 *}$ and Chung-Yi $\mathrm{LI}^{4,5}$ \\ ${ }^{1}$ Department of Dentistry, Sin Lau Christian Hospital, Taiwan \\ ${ }^{2}$ Department of Public Health, College of Medicine, Fu-Jen Catholic University, Taiwan \\ ${ }^{3}$ Department of Surgery, Taipei City Hospital, Taiwan \\ ${ }^{4}$ Department of Public Health, College of Medicine, National Cheng Kung University, Taiwan \\ ${ }^{5}$ Department of Public Health, College of Public Health, China Medical University, Taiwan
}

Received January 22, 2011 and accepted June 8, 2012

Published online in J-STAGE August 8, 2012

\begin{abstract}
We conducted a cohort study of 7,760 dentists in Taiwan between 2003 and 2007 to assess the risk of outpatient visit among dentists. Control groups included physicians and other health personnel. Over the 5-yr study period, the dentist cohort made a total of 270,712 outpatient visits, representing an incidence rate of 7,038 visits $/ 10^{3}$ person-years. Compared to physicians, dentists experienced a significantly reduced covariate adjusted rate ratio (ARR) for all-cause visits $(A R R=0.59,95 \% C I=0.58-0.59)$, as well as for nearly all other causes, except neoplasm (ARR=1.06, $95 \% \mathrm{CI}=1.02-1.09)$. Compared to other health personnel, the dentists still experienced a significantly reduced $A R R$ for all causes (ARR=0.70), but had a slightly but significantly increased risk for endocrine/metabolic/immunity $(A R R=1.04,95 \% C I=1.02-1.05)$ and mental $(A R R=1.04$, 95\%CI=1.01-1.07) disorders. Although the dentists in Taiwan utilized lesser outpatient visits than did their medical colleagues, they tended to have slightly higher rates of outpatient visits for neoplasm, endocrine/metabolic/immunity disorders, and mental illnesses. Policy makers and hospital administrators must not overlook dentists' potentially unseen health problems. A mandatory periodical physical examination for dentists can seriously be considered.
\end{abstract}

Key words: Outpatient visit, Dentists, Epidemiology, Health personnel, Incidence rate, Physicians

\section{Introduction}

Like many other health care workers, dentists are in the forefront position of health care system and their health is critical to the quality of oral care received by patients. Compared to the general population, dentists were frequently found to experience lower rates of morbidity and

*To whom correspondence should be addressed.

Ming-Chung KO and Chung-Yi LI contributed to this article equally. E-mail:mingchung77@gmail.com

(C)2012 National Institute of Occupational Safety and Health mortality, mainly due to their relatively healthy lifestyle and better knowledge in disease prevention ${ }^{1-3}$. Despite that, the health of dentists should not be overlooked because it has been well recognized that various occupational and work environmental hazards could pose adverse effects

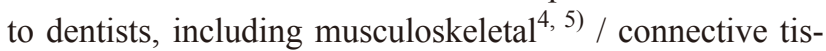
sue $^{6)}$ disorders, skin disease ${ }^{7)}$, metabolic disorder ${ }^{8)}$, infection $^{9-11)}$, gastroenterological disorder ${ }^{12)}$, and cancer ${ }^{13,14)}$. Sporadic reports also suggested increased risks of suicide in dentists because of stress, burnout, depressive symptoms associated with dental practice ${ }^{15,16)}$, and of miscarriage in female dentists due to occupational exposure to certain work related hazards such as acrylate compounds, 
mercury amalgam, solvents or disinfectants ${ }^{17)}$.

Since the launch of the National Health Insurance (NHI) program in 1994, the health services industry in Taiwan has changed dramatically. The universal health insurance removed barriers to health care for those newly insured, enabling them more access to health care. By the end of 2004, more than $98 \%$ of the Taiwanese people were covered by the NHI program ${ }^{18)}$. The annual medical statistics showed that the annual prevalence rate of dental visit in Taiwan increased from $32.0 \%$ in 1999 to $42.7 \%$ in $2008^{19}$. Due to increased demand in the health care environment, the health care personnel have encountered heavy workload strain and psychosocial demand ${ }^{20)}$. Taiwan's dentists also seemed to experience higher workloads than their counterparts in Western nations. According to the 2009 World Health Organization Statistical Information System Report ${ }^{21)}$, the US had the most adequate provision of dentists in the world in 2000-2007, with a figure of 16 dentists / 10,000 people, followed by Canada and Greek (both were 12 dentists / 10,000 people). In Asia, the dentist density was relatively low, with higher figures noted in Japan (7 dentists / 10,000 people) and Philippine (6 dentists / 10,000 people). The figure for Taiwan was 4.28 dentists $/ 10,000$ people $^{21)}$. Additionally, the annual prevalence rate $(42.7 \% \text { in } 2008)^{19)}$ of dental visit in Taiwanese was similar to those reported in some European nations areas including Ireland (40.90\%), France (48.39\%) and Belgium (49.69\%), higher than the figures of Poland (23.76\%), Spain (25.37\%), and Italy (36.76\%), but much lower than those reported in others including The Netherlands (65.73\%), Germany (75.64\%), Sweden (81.55\%), Switzerland (73.73\%), and Denmark $(80.43 \%)^{22)}$. Epidemiological evidence has shown that heavy work load is associated not only with elevated risks of mental disorders but also with adverse effects from diseases of the circulatory system through triggering the release of catecholamine and increased blood pressure, both of which are known risk factors for cardiovascular diseases ${ }^{23)}$.

Morbidity and mortality have been frequently investigated previously in Taiwan to associate various health care professionals including physicians ${ }^{24)}$, nurses ${ }^{25)}$, and physicians of Chinese medicine ${ }^{26)}$. Despite acknowledging the work related hazards in clinical settings and the increasing heavy workload among the dentists in Taiwan, there have been little information concerning the morbidity of Taiwanese dentist population. This study used the NHI claim data with a cohort study design to investigate this understudied issue, i.e., the risk of outpatient visit in the dentist population in Taiwan. Unlike infection/chemi- cal/physical hazards that usually target specific organs, the psychosocial hazards may cause the whole-body effect. Thus, in addition to certain illnesses previously reported to be associated with dental practice, this study was also design to systematically investigate the major disease categories in the dentist population of Taiwan.

\section{Subjects and Methods}

\section{Sources of data}

Data used in this study were retrieved from several claim files of the National Health Insurance Research Database (NHIRD) provided by the Bureau of National Health Insurance (BNHI), Department of Health and managed by the National Health Research Institutes (NHRI). The universal NHI program has been implemented in Taiwan since March 1995. By the end of 1996, more than $96 \%$ of people in Taiwan were covered in the NHI program $^{27)}$ and the Bureau of NHI contracted with $97 \%$ of hospitals and $90 \%$ of clinics all over the nation ${ }^{27)}$. The NHIRD has accumulated eight different registries and eight claims files reported from all contracted hospitals and clinics. Details of both registry and claims files are described elsewhere ${ }^{27)}$. We used the registry for medical personnel (2002), the outpatient claims for 2003 to 2007, and an updated registry for beneficiaries (2003-2007). To ensure the accuracy of the claim files, the BNHI performs expert reviews on a random sample of every 50-100 outpatient and inpatient claims quarterly and false report of diagnosis results in severe penalty from the $\mathrm{BNHI}^{28)}$. The datasets used in this study can be inter-linked by the scrambled unique individual's personal identification number (PIN). The NHRI safeguards the privacy and confidentiality of all beneficiaries and transfers the health insurance data to health researchers after ethical approval has been obtained. In this analysis, access of the NHIRD has been approved by both the NHRI and the Fu-Jen Catholic University Medical School Ethics Review Board (\#C-9703).

\section{Identifications of study subjects and data linkage}

The registry of medical personnel covers information on demographic characteristics and contract status with the NHI for various health professionals including dentists, physicians, physicians of Chinese medicine, pharmacists, nurses, medical laboratory technicians, radiological technologists, speech-language therapists, physical and occupational therapists, and dieticians. Based on the registry of 2002 , a total of 7,760 dentists were identified on the 
last day of 2002, and was used as the study cohort. At the same time, we identified two groups of medical workers as references for comparison. One group consisted of 23,211 physicians who also had contracts with the NHI. The other reference group consisted of 56,788 health personnel other than dentists or physicians.

For each study subject, we linked her PIN to the outpatient visit claim data to retrieve information on outpatient visits between 2003 and 2007. A linkage was considered successful only when the outpatient visit occurring within the period of contract for these three study groups. In total, the cohort of dentists encountered a total of 270,712 outpatient visit in the period of 2003-2007. The number of visits made by physicians and the other health personnel was $1,143,136$ and $2,814,509$, respectively during the same period.

\section{Statistical analysis}

We used the person-year approach under the Poisson assumption to calculate the incidence rate of outpatient visit during the follow-up period. The incidence rate was calculated for all causes as well as for 14 major disease categories based on the International Classification of Disease $9^{\text {th }}$ version, Clinical Modification (ICD-9-CM) codes. Through linkages to the beneficiary registry, we were able to identify the study subjects who terminated their enrollment in the NHI program for various reasons such as mortality and emigration between 2003 and 2007. Termination of the contract with the NHI program for dentists and the subjects from two control groups can also be noticed from the updated registry of medical personnel. The study subjects who were no longer insured in the NHI program were all considered censored in the calculation of personyears being followed for each individual. The person-years observed for each individual was then calculated between January 1, 2003 and either December 31, 2007 (for those uncensored) or the date of censoring (for those censored). The total person-years observed for dentists, physicians, and other health personnel were $38,463.8,115,117$, and $281,997.5$, respectively.

To make comparisons of all-cause and cause-specific incidence rates between the dentist group and the two reference groups, we used the log-linear model with the natural logarithm of incidence rate as the dependent variable to fitted grouped data with simultaneously adjusting for age ( 5 categories), gender ( 2 categories), insurance premium (4 categories), place of practice (6 categories), contracted category of affiliation (4 types), and urbanization for the area of practice ( 3 categories) according to the
National Statistics of Regional Standard Classification ${ }^{29)}$. The log-linear model was fitted with standard Poisson distribution assumption and was used to assess the variation of incidence rates of outpatient visit among the three study groups $^{30)}$. The ratio of two incidence rates adjusted for potential confounders (i.e., adjusted rate ratio, ARR) was calculated using the formula $\mathrm{e}^{m}$, where $m$ is the regression coefficient. The ARR was used to estimate the covariate adjusted relative risk in this study. We adjusted geographic variables for presence of an urban-rural difference in accessibility to medical care in Taiwan ${ }^{31)}$. Previous studies indicated that medical personnel with different types of affiliations might experience different job demand and work load, and then might have different adverse health risks ${ }^{20)}$. Adjustment for type of affiliation may have effectively removed the confounding by affiliation. The analyses were performed with SAS v9.1.3 (SAS Institute, Cary, NC, USA), and the level of significance was set an $\alpha$-value of 0.05 .

\section{Results}

The mean age ( $40.1 \pm 8.2 \mathrm{yr})$ of dentists was older than that of other health personnel $(38.0 \pm 8.8 \mathrm{yr})$, but was similar to the mean age of physicians $(40.5 \pm 8.8 \mathrm{yr})$. Male dominance of the study sample was observed in the three study groups, with the greatest women to men ratio noted for physicians (89.0/11.0), followed by dentists (83.2/16.8) and other health personnel (55.3/44.8). Physicians and other health personnel had the highest and lowest mean insurance premium, respectively, and dentists were in between. There were apparent geographic distributions in practice for the three study group. More than a half of dentists (41.7\%) practiced in Taipei city, capital of Taiwan, while the corresponding figures for other health personnel and physicians were somewhat lower at $28.8 \%$ and $37.3 \%$, respectively. Compared with the other two groups, dentists were less likely to be employed at medical centers or hospitals. More than $80 \%$ of dentists worked at clinics (Table 1).

During the 5-yr follow-up period, the incidence rate of outpatient visit for various causes was the lowest for the dentists $\left(7,038\right.$ per $10^{3}$ person-years), followed by the physicians $\left(9,930\right.$ per $10^{3}$ person-years), and other health personnel (9,981 per $10^{3}$ person-years). The later two groups were very similar in rate of outpatient visit (Table 2). Table 2 also compares the rates of all-cause and cause-specific rates of outpatient visit between dentists and physicians, and shows that dentists experienced a significantly reduced 
Table 1. Characteristics of the study subjects

\begin{tabular}{|c|c|c|c|c|c|c|}
\hline & \multicolumn{2}{|c|}{ Dentists } & \multicolumn{2}{|c|}{ Physicians } & \multicolumn{2}{|c|}{ Other health personnel a } \\
\hline No. of study subjects & \multicolumn{2}{|c|}{7,760} & \multicolumn{2}{|c|}{23,211} & \multicolumn{2}{|c|}{56,788} \\
\hline \multirow[t]{2}{*}{ Person-years observed } & \multicolumn{2}{|c|}{$38,463.80$} & \multicolumn{2}{|c|}{$115,117.90$} & \multicolumn{2}{|c|}{$281,997.50$} \\
\hline & $n$ & $\%$ & $n$ & $\%$ & $n$ & $\%$ \\
\hline \multicolumn{7}{|l|}{ Age (yr) } \\
\hline$\leq 29$ & 718 & 9.3 & 2,180 & 9.4 & 10,796 & 19.0 \\
\hline $30-39$ & 3,269 & 42.1 & 9,647 & 41.6 & 23,840 & 42.0 \\
\hline $40-49$ & 2,732 & 35.2 & 7,553 & 32.5 & 15,664 & 27.6 \\
\hline $50-59$ & 917 & 11.8 & 3,130 & 13.5 & 5,473 & 9.6 \\
\hline$\geq 60$ & 124 & 1.6 & 701 & 3 & 1,015 & 1.8 \\
\hline $\bar{x} \pm \mathrm{SD}$ & \multicolumn{2}{|c|}{$40.1 \pm 8.2$} & \multicolumn{2}{|c|}{$40.5 \pm 8.8$} & \multicolumn{2}{|c|}{$38.0 \pm 8.8$} \\
\hline \multicolumn{7}{|l|}{ Gender } \\
\hline Men & 6,455 & 83.2 & 20,665 & 89 & 31,364 & 55.3 \\
\hline Women & 1,305 & 16.8 & 2,541 & 11 & 25,403 & 44.8 \\
\hline \multicolumn{7}{|c|}{ Insurance premium $\left(\mathrm{NTD}^{\mathrm{b}}\right.$ ) } \\
\hline$<40,100$ & 1,162 & 15.0 & 1,733 & 7.5 & 17,194 & 30.3 \\
\hline $40,100-<55,400$ & 1,397 & 18.0 & 4,672 & 20.1 & 17,278 & 30.4 \\
\hline $55,400-<87,600$ & 2,722 & 35.1 & 5,932 & 25.6 & 9,955 & 17.5 \\
\hline$\geq 87,600$ & 2,479 & 32.0 & 10,874 & 46.9 & 12,361 & 21.8 \\
\hline $\bar{x} \pm \mathrm{SD}$ & \multicolumn{2}{|c|}{$60,845.0 \pm 23,679.5$} & \multicolumn{2}{|c|}{$67,730.2 \pm 22,240.3$} & \multicolumn{2}{|c|}{$50,909.0 \pm 24,541.5$} \\
\hline \multicolumn{7}{|l|}{ Place of practice } \\
\hline Taipei & 3,232 & 41.7 & 8,658 & 37.3 & 16,368 & 28.8 \\
\hline North & 871 & 11.2 & 3,126 & 13.5 & 8,384 & 14.8 \\
\hline Central & 1,555 & 20.0 & 4,170 & 18 & 11,260 & 19.8 \\
\hline South & 804 & 10.4 & 2,874 & 12.4 & 10,589 & 18.7 \\
\hline Kao-Pin & 1,168 & 15.1 & 3,744 & 16.1 & 8,460 & 14.9 \\
\hline East & 130 & 1.7 & 639 & 2.8 & 1,727 & 3.0 \\
\hline \multicolumn{7}{|l|}{ Type of affiliation } \\
\hline Medical center & 709 & 9.1 & 7,772 & 33.5 & 12,360 & 21.8 \\
\hline Regional hospital & 497 & 6.4 & 5,333 & 23 & 10,698 & 18.8 \\
\hline Local hospital & 284 & 3.7 & 3,572 & 15.4 & 11,374 & 20.0 \\
\hline Clinics & 6,270 & 80.8 & 6,534 & 28.2 & 22,356 & 39.4 \\
\hline \multicolumn{7}{|l|}{ Urbanization } \\
\hline Metropolitans & 4,634 & 59.7 & 13,974 & 60.2 & 30,231 & 53.2 \\
\hline Satellite cities & 2,002 & 25.8 & 5,256 & 22.6 & 13,777 & 24.3 \\
\hline Rural areas & 1,124 & 14.5 & 3,981 & 17.2 & 12,780 & 22.5 \\
\hline
\end{tabular}

a Including physicians of Chinese medicine, pharmacists, nurses, medical laboratory technicians, radiological technologists, speech-language therapists, physical and occupational therapists, and dieticians.

b NTD=New Taiwan Dollars, 32 NTD $\approx 1$ USD; insurance premium was determined according to individual's monthly income.

ARR of not only all-cause outpatient visit (ARR $=0.59$, $95 \%$ CI $0.58,0.59$ ), but also visits for illnesses related to infection $(A R R=0.56)$, nerve $(A R R=0.79)$, circulation ( $A R R=0.85)$, respiratory tract $(A R R=0.49)$, digestive system $(\mathrm{ARR}=0.52)$, genitourinary system $(\mathrm{ARR}=0.89)$, skin $(\mathrm{ARR}=0.86)$, musculosketal system $(\mathrm{ARR}=0.62)$, and injury (ARR=0.69). On the other hand, dentists had a modestly but significantly higher rate of outpatient visit for neoplasm (ARR $=1.06,95 \%$ CI 1.02, 1.09).
Table 3 shows significantly reduced ARRs for all-cause outpatient visit $(0.70,95 \%$ CI $0.69,0.70)$ and for various causes including infection ( $\mathrm{ARR}=0.66$ ), nerve disease (ARR $=0.86)$, circulatory illness $(A R R=0.90)$, respiratory illness $(\mathrm{ARR}=0.61)$, digestive illness $(\mathrm{ARR}=0.62)$, genitourinary disorder $(A R R=0.85)$, skin disease $(\mathrm{ARR}=0.79)$, musculosketal disorder $(\mathrm{ARR}=0.65)$ and injury (ARR=0.72) among dentists, as compared to other health personnel. On the other hand, dentists were noted 
Table 2. Comparisons of rates of all-cause and cause-specific outpatient visit between dentists and physicians, 2003-2007

\begin{tabular}{|c|c|c|c|c|c|c|c|c|}
\hline & \multicolumn{2}{|c|}{ Physicians ${ }^{a}$} & \multicolumn{2}{|c|}{ Dentists } & \multicolumn{2}{|c|}{ Crude estimates } & \multicolumn{2}{|c|}{ Adjusted estimates } \\
\hline & $\begin{array}{c}\text { No. of } \\
\text { outpatient visit }\end{array}$ & $\begin{array}{l}\text { Incidence } \\
\text { rate }^{c}\end{array}$ & $\begin{array}{c}\text { No. of } \\
\text { outpatient visit }\end{array}$ & $\begin{array}{l}\text { Incidence } \\
\text { rate }^{c}\end{array}$ & $\mathrm{RR}^{\mathrm{d}}$ & $95 \% \mathrm{CI}^{\mathrm{d}}$ & $\mathrm{RR}^{\mathrm{d}}$ & $95 \% \mathrm{CI}^{\mathrm{d}}$ \\
\hline All causes & $1,143,136$ & 9,930 & 270,712 & 7,038 & 0.72 & $0.71-0.72$ & 0.59 & $0.58-0.59$ \\
\hline Infection (001-139) & 275,350 & 2,392 & 59,551 & 1,548 & 0.67 & $0.66-0.68$ & 0.56 & $0.55-0.56$ \\
\hline Neoplasm (140-239) & 18,588 & 161 & 6,238 & 162 & 1.08 & $1.05-1.12$ & 1.06 & $1.02-1.09$ \\
\hline Endocrine (240-279) & 80,889 & 703 & 22,853 & 594 & 0.98 & $0.97-0.99$ & 0.98 & $0.96-1.00$ \\
\hline Blood (280-289) & 2,447 & 21 & 781 & 20 & 1.17 & $1.08-1.26$ & 1.07 & $0.98-1.18$ \\
\hline Mental (290-319) & 24,657 & 214 & 6,930 & 180 & 1.17 & $1.14-1.21$ & 1.00 & $0.97-1.03$ \\
\hline Nerve (320-389) & 70,789 & 615 & 21,767 & 566 & 0.89 & $0.88-0.91$ & 0.79 & $0.78-0.81$ \\
\hline Circulation (390-459) & 66,006 & 573 & 15,835 & 412 & 0.89 & $0.87-0.90$ & 0.85 & $0.83-0.86$ \\
\hline Respiratory (460-519) & 300,849 & 2,613 & 64,377 & 1,674 & 0.66 & $0.65-0.66$ & 0.49 & $0.49-0.50$ \\
\hline Digestive (520-579) & 85,036 & 739 & 16,772 & 436 & 0.66 & $0.65-0.68$ & 0.52 & $0.51-0.53$ \\
\hline Genitourinary (580-629) & 25,255 & 219 & 9,784 & 254 & 1.00 & $0.98-1.03$ & 0.89 & $0.87-0.92$ \\
\hline Pregnancy (630-676) & 2,468 & 21 & 1,090 & 28 & 0.99 & $0.92-1.06$ & 0.91 & $0.84-1.00$ \\
\hline Skin (680-709) & 51,761 & 450 & 13,229 & 344 & 0.81 & $0.80-0.83$ & 0.68 & $0.67-0.70$ \\
\hline Musculoskeletal (710-739) & 63,241 & 549 & 13,445 & 350 & 0.70 & $0.68-0.71$ & 0.62 & $0.61-0.63$ \\
\hline Injury (E800-999) & 29,020 & 252 & 6,914 & 180 & 0.77 & $0.75-0.79$ & 0.69 & $0.67-0.71$ \\
\hline
\end{tabular}

${ }^{a}$ Reference group. ${ }^{\mathrm{b}}$ Adjustment for age, sex, insurance premium, place of practice, type of affiliation, and urbanization. ${ }^{\mathrm{c}}$ Per 1,000 person-years.

${ }^{\mathrm{d}} \mathrm{RR}=$ rate ratio; $\mathrm{CI}=$ confidence interval.

Table 3. Comparisons of rates of all-cause and cause-specific outpatient visit between dentists and other health personnel, 2003-2007

\begin{tabular}{|c|c|c|c|c|c|c|c|c|}
\hline & \multicolumn{2}{|c|}{ Other health personnel ${ }^{\mathrm{a}}$} & \multicolumn{2}{|c|}{ Dentists } & \multicolumn{2}{|c|}{ Crude estimates } & \multicolumn{2}{|c|}{ Adjusted estimates ${ }^{b}$} \\
\hline & $\begin{array}{c}\text { No. of } \\
\text { outpatient visit }\end{array}$ & $\begin{array}{l}\text { Incidence } \\
\text { rate }^{c}\end{array}$ & $\begin{array}{c}\text { No. of } \\
\text { outpatient visit }\end{array}$ & $\begin{array}{l}\text { Incidence } \\
\text { rate }^{c}\end{array}$ & $\mathrm{RR}^{\mathrm{d}}$ & $95 \% \mathrm{CI}^{\mathrm{d}}$ & $\mathrm{RR}^{\mathrm{d}}$ & $95 \% \mathrm{CI}^{\mathrm{d}}$ \\
\hline All causes & $2,814,509$ & 9,981 & 270,712 & 7,038 & 0.71 & $0.71-0.71$ & 0.70 & $0.69-0.70$ \\
\hline Infection (001-139) & 625,361 & 2,218 & 59,551 & 1,548 & 0.73 & $0.72-0.74$ & 0.66 & $0.65-0.66$ \\
\hline Neoplasm (140-239) & 60,738 & 215 & 6,238 & 162 & 1.04 & $1.01-1.07$ & 1.02 & $0.99-1.05$ \\
\hline Endocrine (240-279) & 147,626 & 524 & 22,853 & 594 & 1.25 & $1.23-1.26$ & 1.04 & $1.02-1.05$ \\
\hline Blood (280-289) & 11,086 & 39 & 781 & 20 & 1.11 & $1.03-1.19$ & 1.05 & $0.98-1.14$ \\
\hline Mental (290-319) & 61,882 & 219 & 6,930 & 180 & 1.20 & $1.17-1.23$ & 1.04 & $1.01-1.07$ \\
\hline Nerve (320-389) & 179,847 & 638 & 21,767 & 566 & 0.93 & $0.91-0.94$ & 0.86 & $0.85-0.88$ \\
\hline Circulation (390-459) & 114,411 & 406 & 15,835 & 412 & 1.10 & $1.08-1.11$ & 0.90 & $0.89-0.92$ \\
\hline Respiratory (460-519) & 689,280 & 2,444 & 64,377 & 1,674 & 0.71 & $0.71-0.72$ & 0.61 & $0.60-0.61$ \\
\hline Digestive (520-579) & 184,625 & 655 & 16,772 & 436 & 0.78 & $0.77-0.79$ & 0.62 & $0.61-0.63$ \\
\hline Genitourinary (580-629) & 163,935 & 581 & 9,784 & 254 & 0.73 & $0.71-0.74$ & 0.85 & $0.83-0.87$ \\
\hline Pregnancy (630-676) & 23,799 & 84 & 1,090 & 28 & 1.01 & $0.95-1.07$ & 1.06 & $1.00-1.13$ \\
\hline Skin (680-709) & 148,034 & 525 & 13,229 & 344 & 0.81 & $0.80-0.83$ & 0.79 & $0.77-0.80$ \\
\hline Musculoskeletal (710-739) & 157,396 & 558 & 13,445 & 350 & 0.76 & $0.75-0.78$ & 0.65 & $0.64-0.66$ \\
\hline Injury (E800-999) & 77,977 & 277 & 6,914 & 180 & 0.81 & $0.79-0.83$ & 0.72 & $0.70-0.74$ \\
\hline
\end{tabular}

${ }^{a}$ Reference group. ${ }^{b}$ Adjustment for age, sex, insurance premium, place of practice, type of affiliation, and urbanization. ${ }^{\mathrm{c}}$ Per 1,000 person-years.

${ }^{\mathrm{d}} \mathrm{RR}=$ rate ratio; $\mathrm{CI}=$ confidence interval.

to experience slightly, but significantly, increased ARRs for endocrine/metabolic/immunity $(\mathrm{ARR}=1.04,95 \% \mathrm{CI}$ $1.02,1.05)$ and mental (ARR $=1.04,95 \%$ CI 1.01, 1.07) disorders.

\section{Discussion}

This study is believed to be the first health report with all dentists who have a contract with a nationwide NHI program in Taiwan. Taiwan's dentists had an annual average of 7.04 outpatient visits per person between 2003 and 
2007, which was much lower than the figures for physicians (9.93 visits) and for other health personnel (9.98 visits). Also with NHI claims, Chen et al. reported that Taiwanese people had an average of 13.4 outpatient visits per person in 2006 $6^{32}$, indicating that dentists in Taiwan had a very low utilization rate of outpatient visit. Respiratory diseases were the most prevalent cause of outpatient visit for dentists. Other common causes included infection, endocrine/metabolic/immunity disorders, and nervous disease. Despite a lower incidence of all-cause outpatient visits, the dentists did suffer more frequently than control groups from neoplasm, endocrine/metabolic/immunity disease, and mental illness.

The dentists in Taiwan suffered less frequently than physicians from overall and many cause-specific outpatient visits, except neoplasm. Additionally, dentists were also at obviously lesser risks of outpatient visit for all causes and most specific causes, as compared to other health personnel, but were at greater risks of mental disorders and endocrine/metabolism/immunity disease. Lesser overall outpatient visits noted in dentists was unlikely to be entirely attributed by dentists' reluctance to seek appropriate health cares or by their self-treating behaviors, since we included physicians and other health personnel as control groups, who also tend to be reluctant to adopt the role of a patient and concern about confidentiality, which could also impede their access to appropriate health cares and lead to their self-treating ${ }^{33)}$. Our findings may have reflected that dentists are more likely than their medical colleagues to exercise healthy behaviors. It could also be due to lesser exposure to occupational hazards involved in dentists' duties. Although dentists had an obvious reduced rate of overall outpatient visit, they suffered from frequent visits for neoplasm, mental disorders, and endocrine/metabolic/immunity diseases by a magnitude of $4-6 \%$, which however should not be overlooked.

Rix and Lynge ${ }^{34)}$ performed a 17-yr cohort analysis of the Danish Occupational Mortality Register, noting that the overall cancer incidence was elevated in dental practitioners. Male dental practitioners also had significantly higher risks of melanomas of the skin. The breast cancer risk was elevated among female salaried dentists as well. A Japanese study reported that with the general Tokyo residents as a reference population, the standardized mortality ratios for dentists were significantly higher for esophageal and colon cancers ${ }^{35)}$. In addition, several studies also reported an increased risk for skin cancer, especially melanoma, in dentists ${ }^{2}, 36,37$. In a recent meta-analysis, Simning and Wijngaarden reported an estimated relative risk of
$2.4(95 \% \mathrm{CI} 1.6,3.7)$ for melanoma in male dentists, and to a lesser magnitude for female dentists (relative risk $=2.0$, $95 \%$ CI 1.1, 3.9) ${ }^{14)}$. Although some of the previous reports argued that the elevated risks experienced by dentists may be related to social status level ${ }^{2,36,37)}$ or lifestyle (e.g., behavior related to sunlight exposure $)^{22)}$, the review by Simning and Wijngaarden ${ }^{14)}$ still suggested that certain hazards in the workplace may account for such findings. Our study employed physicians and other health personnel as reference groups, whose social status level and lifestyle are similar to dentists, which may have largely, even not entirely, excluded the potential confounding posed by social status level and lifestyle.

The review by Alaujan and Alzahem ${ }^{38)}$ indicated that dentists are faced every day with many stressors; as a result, they are subject to many symptoms of stress that must be identified and managed in the early stages before serious physical and psychological consequences develop. A recent survey of British dentists revealed that the most common factors contributing to stress at work were patient demands (75\%), practice management/staff issues (56\%), fear of complaints/litigation (54\%) and non-clinical paperwork $(54 \%)^{39)}$. A national survey of dentists registered with the Lithuanian Dental Association indicated that fatigue (94.7\%) and back pain (91.0\%) were the most prevalent physical complaints reported ${ }^{40)}$. Of the 256 Mexican dentists, chronic high stress levels were found in 35 (13.7\%) of the dentists, medium level stress in 184 (71.8\%), and a low level of chronic stress in $37(14.5 \%)^{15)}$. In a prospective study, Ahola and Hakanen ${ }^{16)}$ investigated whether burnout may mediate the association between job strain and depressive symptoms in a national sample of Finnish dentists. The results showed that there was a reciprocal relationship between burnout and depressive symptoms, and job strain predisposed to depression through burnout. In comparison, job strain predisposes to burnout directly and via depression. Given a relatively high work load in Taiwan's dentist population, the above findings from various previous studies might explain, at least to some extent, the slightly higher prevalence of outpatient visit for mental illnesses in Taiwan's dentists.

In addition to mental illnesses, dentists were also noted to experience a slightly increased risk of endocrine/ metabolic/immunity disorders, which are probably the most highly lifestyle-related symptoms investigated in this study. A recent British survey showed that more than half $(53 \%)$ of dentists were relatively inactive during the day but $57 \%$ took some form of physical exercise at least 3-4 times per week. Nearly a half (49\%) of respondents 
felt that their level of physical activity was probably inadequate, and was very likely or somewhat likely to cause them health problems ${ }^{37}$. A local study conducted in Taiwan on a sample of hospital employees reported that although the prevalence of metabolic syndrome may be lower in hospital employees than in the general population, the prevalence of metabolic syndrome can still be as high as $10.3 \%$ (21.8\% males, $7.0 \%$ females) among hospital employees, and suggested more efficient health-promotion programs administered to hospital employees to further reduce the metabolic syndrome ${ }^{41)}$. Due to lack of information regarding the work shift and work-related lifestyles of dentists and other health personnel in Taiwan, we were unable to make more specific interpretations of our findings.

Most of the published studies suggesting lower risks of mortality or morbidity among dentists than in the general population are subject to methodological limitations owing to a higher socioeconomic status and healthier lifestyle of dentists. Our current study employed physicians and other health personnel as reference controls may have largely removed such confounding, and balanced the potential problems of self-treating commonly seen in health care workers. Moreover, we further adjusted a number of factors in the multivariate regression model, including age, sex, type of affiliation, and several socio-demographic factors to remove potential confounding. As such, our findings may have better reflected the hazards more directly related to dental work. However, due to limited information regarding specific work contents, work-related lifestyles, and possible occupation related hazards for dentists, we were unable to make specific interpretations regarding what factors that truly caused increased outpatient visit for certain disease among dentists in Taiwan. Additionally, we didn't have complete information on a study subject's history of employment, which also limited the causal inference between dental profession and incidence of outpatient visit.

There is a potential for disease misclassification in claim data. Although the BNHI performed regular checkup for the accuracy of reimbursement, the codes of disease diagnoses in the NHI claims have not been systematically examined. However, the potential disease misclassification is likely to proportionally apply in the three study groups, resulting in a non-differential type of disease misclassification, which will bias, if any, the study findings toward the null, and should not be a valid argument for the increased ARR observed in this study. In conclusion, with such a large dentist cohort and multiple control groups, we noted that the dentists in Taiwan were indeed at greater rates of endocrine/metabolic/immunity disease, mental illness, and neoplasm, which needs more investigations. Future studies of dentists' health would also benefit from the assessment of specific occupational exposures rather than relying on job title alone. Besides, whether the findings found in this study were specific to Taiwanese dentists or can be applicable to dentists of other nations also deserved further investigations. Policy makers and hospital administrators must not overlook dentists' potentially unseen health problems. A mandatory periodical physical examination for dentists can seriously be considered.

\section{Acknowledgements}

This study was supported by grants from National Scientific Council (NSC98-2314-B-227-001-MY2). The interpretation and conclusions contained herein do not represent those of BNHI, Department of Health or NHRI.

\section{References}

1) Zwemer JD, Williams JE (1987) Dentist health status and risks. J Am Coll Dent 54, 7-12. [Medline]

2) Andersen A, Barlow L, Engeland A, Kjærheim K, Lynge E, Pukkala E (1999) Work-related cancer in the Nordic Countries. Scand J Work Environ Health 25 (Suppl 2), 1-116. [Medline]

3) Simning A, van Wijngaarden E (2007) Literature review of cancer mortality and incidence among dentists. Occup Environ Med 64, 432-8. [Medline] [CrossRef]

4) Leggat PA, Smith DR (2006) Musculoskeletal disorders self-reported by dentists in Queensland, Australia. Aust Dent J 51, 324-7. [Medline] [CrossRef]

5) Kierklo A, Kobus A, Jaworska M, Botuliński B (2011) Work-related musculoskeletal disorders among dentists a questionnaire survey. Ann Agric Environ Med 18, 79-84. [Medline]

6) Ding H, Solovieva S, Vehmas T, Takala EP, Leino-Arjas P (2010) Hand osteoarthritis and pinch grip strength among middle-aged female dentists and teachers. Scand J Rheumatol 39, 84-7. [Medline] [CrossRef]

7) Kurpiewska J, Liwkowicz J, Benczek K, Padlewska K (2011) A survey of work-related skin diseases in different occupations in Poland. Int J Occup Saf Ergon 17, 207-14. [Medline]

8) Palacios-Rodríguez RG, Paulín-Villalpando P, LópezCarmona JM, Valerio-Acosta Mdel M, Cabrera-Gaytán DA (2010) Metabolic syndrome in health care personnel from a primary care unit. Rev Med Inst Mex Seguro Soc 48, 297-302 (in Spanish). [Medline]

9) Neguț EA, Bălteanu M, Ionescu G, Băncescu A, Iliescu A, Skaug N (2007) Control of blood-transmitted infections in dentistry. Roum Arch Microbiol Immunol 66, 26-36. [Medline] 
10) Nagao Y, Matsuoka H, Kawaguchi T, Ide T, Sata M (2008) $\mathrm{HBV}$ and HCV infection in Japanese dental care workers. Int J Mol Med 21, 791-9. [Medline]

11) Azodo CC, Ehigiator O, Ojo MA (2010) Occupational risks and hepatitis $\mathrm{B}$ vaccination status of dental auxiliaries in Nigeria. Med Princ Pract 19, 364-6. [Medline] [CrossRef]

12) Loster BW, Czesnikiewicz-Guzik M, Bielanski W, Karczewska E, Loster JE, Kalukin J, Guzik TJ, Majewski S, Konturek SJ (2009) Prevalence and characterization of Helicobacter pylori (H. pylori) infection and colonization in dentists. J Physiol Pharmacol 60, 13-8. [Medline]

13) Tanaka H, Nishio N, Tokunaga R, Tsukuma H (2004) Liver cancer risk in Japanese male dentists: a long-term retrospective cohort study. J Occup Health 46, 398-402. [Medline] [CrossRef]

14) Nishio N, Tanaka H, Tsukuma H, Tokunaga R (2004) Lung cancer risk in male dentists: a retrospective cohort study in Japan, 1964-1997. J Occup Health 46, 37-42. [Medline] [CrossRef]

15) Pozos Radillo BE, Tórrez López TM, Aguilera Velasco Mde L, Acosta Fernández M, González Perez GJ (2008) Stress-associated factors in Mexican dentists. Braz Oral Res 22, 223-8. [Medline] [CrossRef]

16) Ahola K, Hakanen J (2007) Job strain, burnout, and depressive symptoms: a prospective study among dentists. J Affect Disord 104, 103-10. [Medline] [CrossRef]

17) Lindbohm ML, Ylöstalo $P$, Sallmén M, Henriks-Eckerman ML, Nurminen T, Forss H, Taskinen H (2007) Occupational exposure in dentistry and miscarriage. Occup Environ Med 64, 127-33. [Medline] [CrossRef]

18) Department of Health, Division of Health Statistics (2005) Trend of health statistics in Taiwan. Department of Health, Executive Yuan, Taiwan.

19) Department of Health. Annual report of medical statistics. http://www.doh.gov.tw/CHT2006/DM/DM2_2_p02. aspx?class_no $=440 \&$ now_fod_list_no $=12020 \&$ level no $=3 \&$ doc_no=81948. Accessed January 16, 2012.

20) Lin YW, Chang YW, Tsai CC (2004) Job strain and healthrelated quality of life of hospital employees: case of a medical canter in Taichung. Taiwan J Public Health 23, 108-20.

21) World Health Organization (2009) Health workforce, infrastructure, essential medicines. 95-105, WHO Press, Geneva.

22) Listl S, Moran V, Maurer J, Faggion CM Jr (2012) Dental service utilization by Europeans aged 50 plus. Community Dent Oral Epidemiol 40, 164-74. [Medline] [CrossRef]

23) Karasek RA, Theorell T (1990) Health work stress, productivity and the reconstruction of working life. Basic Books, New York.

24) Lin CM, Yang CH, Sung FC, Li CY (2008) Risks of hospitalization among physicians in Taiwan. Health Serv Res 43, 675-92. [Medline] [CrossRef]

25) Huang IC, Yang CH, Sung FC, Chen HF, Li CY (2009) Risks of ambulatory cares among female nursing staffs in
Taiwan. J Clin Nurs 18, 1207-16. [Medline] [CrossRef]

26) Liu SH, Li TH, Lin YL, Shiao YJ, Wu SC, Li CY, Sung FC, Yang CY, Wu TN (2009) Morbidity and disease risk among the Chinese medicine physicians in Taiwan. Tohoku J Exp Med 219, 207-14. [Medline] [CrossRef]

27) Department of Health, Division of Health Statistics (2003) Trend of health statistics in Taiwan. Department of Health, Executive Yuan, Taiwan.

28) Bureau of National Health Insurance. NHI Statistics. http://www.nhi.gov.tw/information/bulletin file/421_0890036465-19.doc. Accessed October 1, 2010.

29) Directorate-General of Budget (1993) National statistics of regional standard classification data. Taipei, Taiwan. Directorate-General Budget, Accounting and Statistics, Executive Yuan.

30) Holford TR (1983) The estimation of age, period and cohort effects for vital rates. Biometrics 39, 311-24. [Medline] [CrossRef]

31) Tan HF, Tseng HF, Chang CK, Lin W, Hsiao SH (2005) Accessibility assessment of the health care improvement program in rural Taiwan. J Rural Health 21, 372-7. [Medline] [CrossRef]

32) Chen TJ, Chou LF, Hwang SJ (2006) Patterns of ambulatory care utilization in Taiwan. BMC Health Serv Res 6, 54-61. [Medline] [CrossRef]

33) Thompson WT, Cupples ME, Sibbett CH, Skan DI, Bradley $\mathrm{T}$ (2001) Challenge of culture, conscience, and contract to general practitioners' care of their own health: qualitative study. BMJ 323, 728-31. [Medline] [CrossRef]

34) Rix BA, Lynge E (1996) Cancer incidence in Danish health care workers. Scand J Soc Med 24, 114-20. [Medline]

35) Shimpo H, Yokoyama E, Tsurumaki K (1998) Causes of death and life expectancies among dentists. Int Dent J 48, 563-70. [Medline] [CrossRef]

36) Firth HM, Cooke KR, Herbison GP (1996) Male cancer incidence by occupation: New Zealand, 1972-1984. Int J Epidemiol 25, 14-21. [Medline] [CrossRef]

37) Eriksson M, Hardell L, Malker H, Weiner J (1998) Increased cancer incidence in physicians, dentists, and health care workers. Oncol Rep 5, 1413-8. [Medline]

38) Alaujan AH, Alzahem AM (2004) Stress among dentists. Gen Dent 52, 428-32. [Medline]

39) Kay EJ, Lowe JC (2008) A survey of stress levels, selfperceived health and health-related behaviours of UK dental practitioners in 2005. Br Dent J 204, E19-28. [Medline] [CrossRef]

40) Puriene A, Aleksejuniene J, Petrauskiene J, Balciuniene I, Janulyte V (2008) Self-reported occupational health issues among Lithuanian dentists. Ind Health 46, 369-74. [Medline] [CrossRef]

41) Ho HH, Tsai TY, Lin CL, Wu SY, Li CY (2011) Prevalence and associated factors for metabolic syndrome in Taiwanese hospital employees. Asia Pac J Public Health 23, 307-14. [Medline] [CrossRef] 